\title{
DESIGN THINKING, SYSTEM THINKING, GROUNDED THEORY, AND SYSTEM DYNAMICS MODELING-AN INTEGRATIVE METHODOLOGY FOR SOCIAL SCIENCES AND HUMANITIES ${ }^{1}$
}

\author{
EVA ŠVIRÁKOVÁ, GABRIEL BIANCHI
}

\begin{abstract}
This paper concerns design thinking (Lawson, 1980), system thinking (systems theory) (von Bertalanffy, 1968), and system dynamics modeling as methodological platforms for analyzing large amounts of qualitative data and transforming it into quantitative mode. The aims of this article are to present an integral (mixed) research process including the design thinking process-a solution oriented approach applicable in the social sciences and humanities which enables to reveal causality in research on societal and behavioral issues. This integral approach is illustrated by an empirical pilot study from art/design-educational environment.
\end{abstract}

Key words: design thinking; system thinking; system dynamic modeling; causality; social sciences; epistemology; qualitative and quantitative analysis.

\section{Introduction}

This paper concerns design thinking (Lawson, 1980), system thinking (systems theory) (von Bertalanffy, 1968), and system dynamics modeling as methodological platforms for analyzing large amounts of qualitative data and transforming it into quantitative mode. The aim is to reveal causality in research on societal and behavioral issues.

Production models and prototypes are part of the design process (Ambrose et al., 2011; Knapp et al., 2016). Product designers use models and prototypes to verify the extent to which the design meets customer demands. Since the publication of B. Lawson's How Designers Think (1980) design thinking has moved away from the material environment and into the arena of economics and social issues, and the focus has shifted from "problem thinking" to "solution thinking". Models and theories are the highest level of abstraction in analytical thinking. According to Sterman (1991), we use mental models every day without realizing it. Our decision-making and actions are not based on the real world but

1 This work was supported by the Slovak research agency VEGA, project No 2/0027/17. 
on mental images of the external world, relationships between the different elements, and ideas about the consequences of our actions (causality). However, it is hard to interpret mental models comprehensively and unequivocally. The main argument for using computer modeling is that ambiguous interpretations of mental models are not scientific. Computer modeling enables us to assess behavior occurring within a particular process observed in the social environment. It can be used to evaluate a decision strategy and predict behavior in any social and economic system. Computer models are explicit, while modeling results is specific. The modeling conditions are set out in the instructions and are available to users. Computer models process the logical consequences of all the conditions entered into the model. Computer models are comprehensible and can process many factors at a time and display them on a timeline. A model is a quantitative abstraction of qualitative relations. However, computer models have limitations: they can become a "black box" in which incomprehensible processes may occur.

The aims of this article are to present an integral (mixed) research process including the design thinking process - a solution-oriented approach applicable in the social sciences and humanities. More specifically, it is about creating a system dynamics model in which the steps whereby it was created are comprehensible, logical and can be verified throughout the process of creation. The mental model is transformed into a quantitative format using system dynamics. The research process has been designed with the aim of creating a simulation that reflects real situations within the environment being observed.

\section{Recent research}

Projects aimed at new product design involve a great degree of creativity. The visible and invisible elements of this system are linked through the design process activities. According to Ambrose and Harris (2011), and Knapp, Zeratsky, and Kowitz (2016) a number of stages are involved but all design processes share one thing in common: design thinking-a customer-focused way of thinking. In the design process we often create models or prototypes to check with the buyer whether the design meets the client's expectations and whether the client will in fact buy the product. A project which results in product innovation is considered to be a system and so we are led into systems thinking. In this study both types of thinking are combined, and a new model is created. It is a mental model and cannot be presented as a three-dimensional one, unlike the models used in design studios. It is a model that is a design thinking system product. It can be used to solve problems and challenges hidden in the design process using a qualitative approach.

The assumption in this study is that a system dynamics model can be created using the Causal Loop Diagram (CLD) and then applied to qualitative data extracted using open and axial coding, based on Grounded Theory. The CLD enables us to create a map of the causal structure based on initial hypotheses, key variables, reference modes and other available data (Sterman, 1996). It can also be used to present a dynamic hypothesis of the expected findings.

Vemuri and Bellinger (2017) use the systems model approach in social science research, analyzing the spirit, mind and body (SMB) of an organization. They examined the need for a systemic approach to successfully incorporating systems thinking into an organization. 
Simonsen and Friberg (2014) present two techniques to improve the collective analysis of large amounts of qualitative data, affinity diagramming and diagnostic mapping. Their research approach involves collecting qualitative data and interpreting that data using data coding. This is the approach partly applied in this article. In their study Bureš and Rácz (2017) use system dynamics modeling to identify behavioral stereotypes. They obtained data from interviews and subsequently analyzed them to identify the main areas and then fed these into Causal Loops Diagrams. In her study on software piracy Mildeová (2013) identified the key elements of software piracy in the causal loop: ethics, costs, sales, financial stability, company development and prices. A similar methodology is used in this study. In a CLD the main question concerns the influence the elements have in the cycle. Richardson (1986) provides the following definition of a positive influence in a Causal Loop Diagram: "A has a positive influence on B if an increase (decrease) in A results in a value of B which is greater (less) than it would be had A not changed." The causal consequences in the loop are positive if an increase in A results in an increase in B, and are negative if an increase in A results in a decrease in B (and vice versa).

\section{Research method}

In order to test the integration of design thinking and the system dynamics approach we conducted a study of the processes in a trainee design studio (attended by 85 studentsparticipants). The main elements of our research interest were the processes and interactions between the students and teachers.

\section{Stage 1: Creative Questionnaire}

In November 2016 we asked 85 design students to complete a creative questionnaire containing specific visual elements. We received 65 completed questionnaires. In the survey we assumed that the students' goal was to submit an assignment set by the supervisor, pass the studio exam, and obtain credits. In other words, we assumed the aim of the design process was to create a creative product that would be evaluated as of value to the customer, or consumer. We asked, for instance, the following questions: What situations did you have to deal with during the design process to achieve a quality outcome? What problems and issues did you have to deal with during the design process? What helped you and what hindered you during the design process? All the questionnaires were read by the researchers.

\section{Stage 2: Interviews}

In January and February 2017, we selected a questionnaire completed by a student who had succeeded at innovation transfer and we proceeded to the second part of the survey: interview with the designer of a product. We decided to conduct the interview with the designer of a fashion collection. We recorded the interview so it could then be transcribed verbatim. The interview was designed so as to provide deeper insight into the questionnaires and to enable us to best interpret the responses. 


\section{Stage 3: Transcription of the data from the questionnaires and interview (March-May 2017)}

The data were transcribed into separate sentences. The transcripts contained links to the source questionnaire and to the interview. The follow-up phase was the data analysis (June - December 2017): the data were analyzed using open, axial and selective coding from the Grounded Theory method. The next step was to transform the qualitative data into Causal Loops Diagrams. The last stage of the research was to create a System Dynamics Model. In this stage (January - February 2018), the data were transformed from mind maps into a quantitative format.

\section{Stage 4: Open, axial and selective coding}

Grounded Theory is a qualitative research method that is typically used to develop a theoretical and conceptual understanding of social and interpersonal effects. The Grounded Theory approach is used to evaluate the system and to add credibility to the research process. Based on a recommendation by Strauss and Corbin (1999) we analyzed, conceptualized and then reconstituted the data. The data from the questionnaires were analyzed using open coding. We categorized each sentence. The question we asked throughout the analysis was: What is the main idea expressed by this sentence (Strauss \& Corbin, 1999)? Key concepts were assigned to the sentences and then the sentences were put in categories (groups). Each category represented a different situation or problem, for example incorporating practice into the design process, perceived time available. Next, axial coding was used to evaluate the links between the categories. The template used was: "A causes B", which also involves polarity, according to Richardson and Pugh (1981). In general, it can be said that If A occurs, then B increases; or if A occurs, then B drops. The polarity was indicated by placing (+) or (-) near the arrow. The third technique from the Grounded Theory approach is selective coding. In this technique a central category is chosen, which is then systematically introduced into a relationship with the other categories. The idea targeted by the research question was chosen as the central category. In this case, it was the quality of the result of the design process. The central category should be measurable in physical units (pcs, people, etc.). During this process the core of the system dynamics model is created, which means a variable is chosen that is crucial to the answer to the key question. This variable is not just the key point of interest to the researchers; it is also the key variable for the graphic display of the modeled problem dynamics.

\section{Stage 5: Systems thinking application}

Thinking that has no feedback impacts on decisions and subsequent events is known as 'thinking in open line'. Until now it has not been possible to have feedback loops in the mental model. Sterman (1991) suggests the modeling process contains five steps: (1) Problem Articulation; (2) Formulation of Dynamic Hypothesis; (3) Formulation of a Simulation Model; (4) Testing: Does the model reproduce the problem behavior adequately for my purpose? (5) Policy Design and Evaluation with scenario specification: What environmental conditions might arise? This article is concerned with the second step (the 
Formulation of Dynamic Hypothesis) and describes the procedure for developing a causal structure that uses the Causal Loop Diagram and Stock and Flow maps (Sterman, 1991).

The Causal Loop Diagram can be used to help develop a map of the causal structure based on initial hypotheses, key variables, reference modes, and other available data (Sterman, 2000). It may be created using data from questionnaires or interviews and the three coding procedures relating to the Grounded Theory approach (open coding, axial coding and selective coding). The conclusions from the questionnaires are summarized in a Causal Loop Diagram, containing, besides the polarity, the names of the loops (Reinforcing, Balancing, see Fig. 1).

\section{Stage 6: System dynamics modeling}

The system dynamics model presumes that every change affects a monitored variable that is crucial to the result. All simulation models have two parts (Sterman, 1991). First, they must contain the relevant elements of the field they deal with. Secondly, they must express the behavior of these elements found in previous analysis.

The Stock and Flow Diagram contains the numerical data generated in the model and shows the behavior of the system in relation to time. The gist of the is model expressed by the relationship between two or three elements of the system in CLD (see Figure 6). The quality of the design process outcome is the core of the model that we aim for in the system. All students want to achieve the best possible outcome for the studio design process. Therefore the quality of the design process outcome lies at the center of the mental map. We assume that the quality of the outcome increases. In the language of systems thinking this is called a reinforcing loop. This way the model is clear. The aim is to establish the cause of growth and reduce the quality of the design process outcome. The core of the model is specified during the systems thinking process. It also depicts the education process in the studios. Graphs generated from the Stock and Flow Diagram show how the variables evolve in relation to time and on the basis of the numerical data entered into the model. The main variable is the central category that is represented as a stock in the system dynamics model. Stocks can be changed only by flow (Stock and Flow Diagram).

\section{Results: The procedure}

The process described above was tested in practice using the case study presented in the empirical section of the article. The process of obtaining a successful solution to a creative project and putting it into practice is complex and takes time. There were five steps to analyzing the research data. The first three steps-the open, axial, and selective coding - are derived from the Grounded Theory method. The fourth step is to construct the Causal Loop Diagram and the last step is to convert that into a Stock Flow Diagram.

\section{Step 1: Open coding}

The image below (Figure 2) shows a creative questionnaire completed by a respondent from the fashion design studio. Below we present the questionnaire and interview with the student A.M. (female). 
... mmcité company set detailed assignment..., mmcité consultations, specitic reviews and first proposals..., consultations are not enough for me, in such a project it is necessary to have a continual contact with practice, with people that solve these issues. ...dilemma: to be economical with water versus to redesign an existing design, frustration, a lack of time, studios lessons were cancelled.......another project keeps me busy..., frustration, a lack of time, studios lessons were cancelled, I do not have enough technical knowledge..., other subjects, other studios' tasks, my part-time job..., the biggest barrier are other school projects, therefore $i t$ is not possible to work fully...Maybe lack of time pressure, due to other tasks, my own hobbies, my own activities that I organize...soft sitting, market /analysis and the first sketches, visually functional model manufacturing..., deeper analysis of soft sitting project, to familiarize with requirements of the client - RIM company, four solutions chosen for the client, and their drafts...a head of studio did not like the idea because I did not know how to deliver the stickers to the customer and how to get this information about water to them...
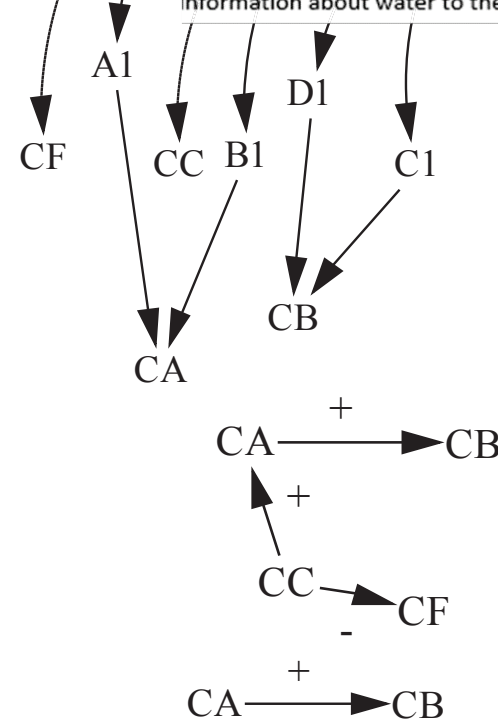
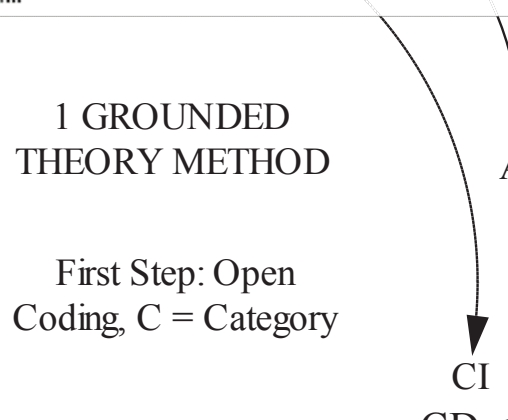

Second Step: Axial Coding

Third Step: Selective Coding thinking in open line
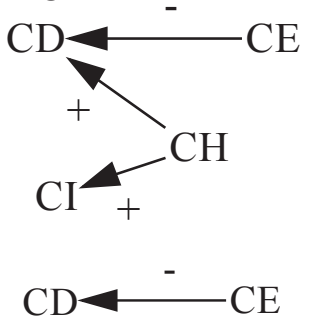

Fourth Step:

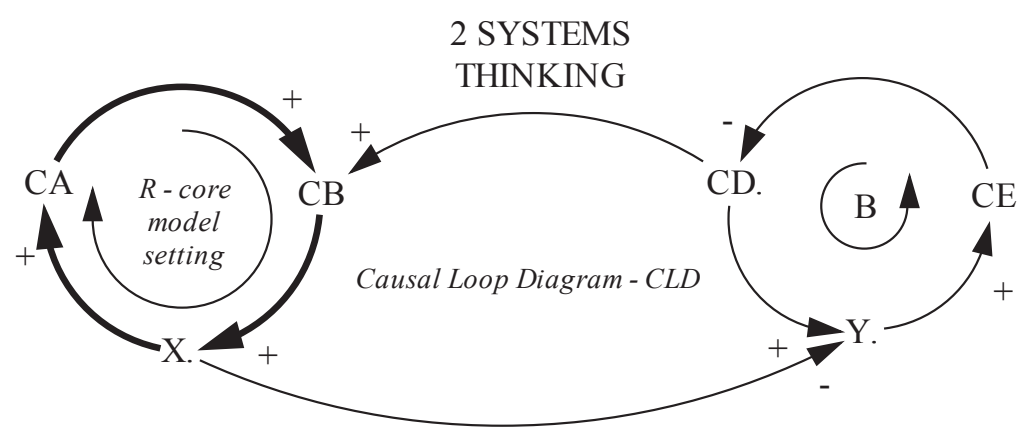

Figure 1. Causality identification path (using qualitative data). Own source, 2017. 


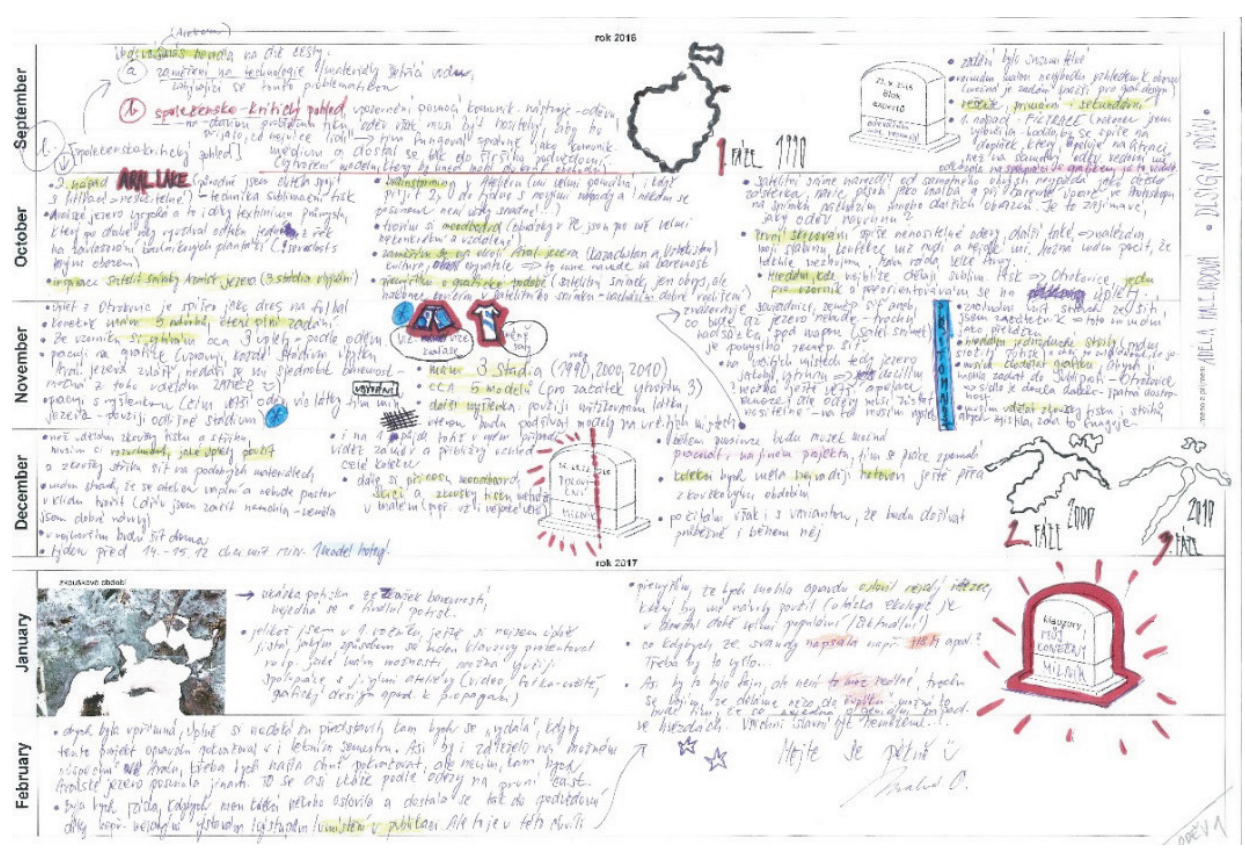

Figure 2. Questionnaire. The Aral Sea problem. (A.M., student, 2016)

Below is a list of the answers from the questionnaires and interview with A.M. (female). The transcripts are authentic.

(1) ...project assignment, collaboration with mmcité, I didn't really understand what we were supposed to do, brainstorming, dividing up into specified groups, narrowing the topic down, ...mmcité set out the assignment in more detail..., mmcité consultations, the research and first drafts...,

(2) ...consultations with mmcité, I guess we misunderstood, confusion, stress...

(3) ...the consultations aren't enough, in a project like this you have to be in continual contact with, with the real thing, the people that solve these issues.

(4) ... research presentation given to mmcité, first suggestion about changing location rejected, further suggestions - rejected, helplessness, inability to come up with anything, fear that everything will be rejected ...

(5) ...dilemma: water management vs. redesign of an existing design, lack of time, studio lessons canceled ...

(6) ....another project keeps me busy..., frustration, lack of time, studio lessons canceled, ... other subjects, other studio work, my part-time job..., the biggest barrier is other school projects, it is impossible to work at full stretch...Fear there's not enough time because of other work, my hobbies and other activities...

(7) ... soft sitting, market analysis and first sketches, making a visually functional model..., ...deeper analysis of the soft sitting project, familiarization with client requirements RIM company, four solutions chosen for RIM for further elaboration... 
(8) ...the head of studio doesn't like my idea much arguing it's not clear how the labels can be delivered to customers ...claiming it won't have any real impact on whether people save water... I had a dream in which I came up with a new idea. After presenting the idea (dream) to the head of the studio I got this feedback $\rightarrow$ "No, don't do this, leave it up to the experts ". Return to the original idea.

(9) Anticipated head's disappointment with my work - the head indicated it at the very start $\rightarrow$ saying it was weak, didn't meet the requirements of the assignment.

(10) ...the idea of waterproof shoes goes down the drain, despair...

(11) ... a bad start to the new semester, no studio lessons, we're waiting for a studio, fear of the head pressurizing me as usual, that I won't make it...,...fear of being expelled from school...

Two researchers performed the coding, working independently. They compared the results of their analysis at each stage of the qualitative research. Selected passages from the questionnaires were assigned into categories (see Table 1). If a group of sentences is put into two different categories, then that signals there is likely to be a causal relationship between the two categories.

Table 1. Possible categorization of groups of sentences Own source, 2018 (Key to Table 1: Category X: list of sentences/items - name of category.)

\begin{tabular}{|l|}
\hline Category A: 1,2,3,4,7 - Practical Experience \\
\hline Category B: 1 - Assignment Quality \\
\hline Category C: 2,4,5,9,10,11 - Chaos, Stress, Frustration, Fear, Despair, Disappointment \\
\hline Category D: 3,5,6,11 - Perceived Available Time \\
\hline Category E: 6,7 - Other Projects \\
\hline Category F: 8 - Influence of Studio Head \\
\hline Category G: 8,9,10 - Quality of Outcome \\
\hline
\end{tabular}

\section{Step 2: Axial coding}

Relations between/among the categories are shown in Figure 3 below.

Axial coding is aimed at identifying possible causal relations between categories. These are identified through the coincidence of items as related to multiple categories/codes. We have identified causal relations between the following categories. The resulting balance of axial coding is shown in the table below (Table 2).

Outcome of the axial coding can also be presented in diagram form. The diagram in Figure 4 shows the vectors/causalities between categories and the polarities (direct and indirect proportion to the causal relation). 


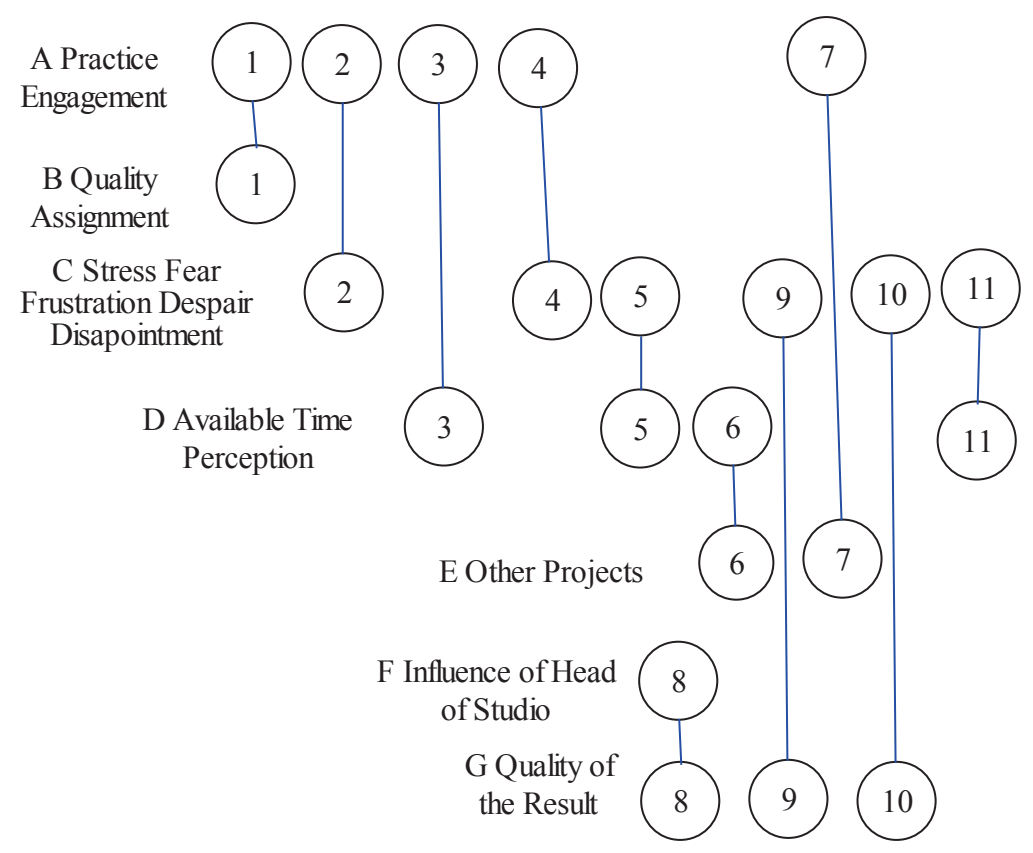

Figure 3. Connections between categories. Own source, 2018.

Table 2. Axial coding showing polarity between the categories. Own source, 2018

\section{Axial coding:}

(1) Practical experience (A) improves assignment quality (B).

(2) Practical experience (A) causes higher risk of misunderstanding which causes more confusion and stress $(\mathrm{C})$.

(3) Practical experience (A) requires more time to be spent on the assignment which reduces the time available for product development (D).

(4) Practical experience (A) leads to a higher risk of rejection which causes more despair, fear (C).

(5) Insufficient time available for product development (D) causes more frustration (C).

(6) Other projects (E) reduce time allocated to product development in the studio (D).

(7) Practical experience (A) leads to the students having other projects (E) to deal with.

(8) Studio head (F) has a direct influence on improving the quality of the outcome $(\mathrm{G})$.

(9) Studio head has a direct influence on reducing disappointment, but disappointment grows as the designs fail to be implemented, meaning the poorer quality $(\mathrm{G})$ the more disappointment $(\mathrm{C})$.

(10) Idea rejected by studio head because the product is not of the appropriate quality (G) and the idea being rejected increases the level of despair (C).

(11) Lack of time for product development (D) causes more fear (C). 


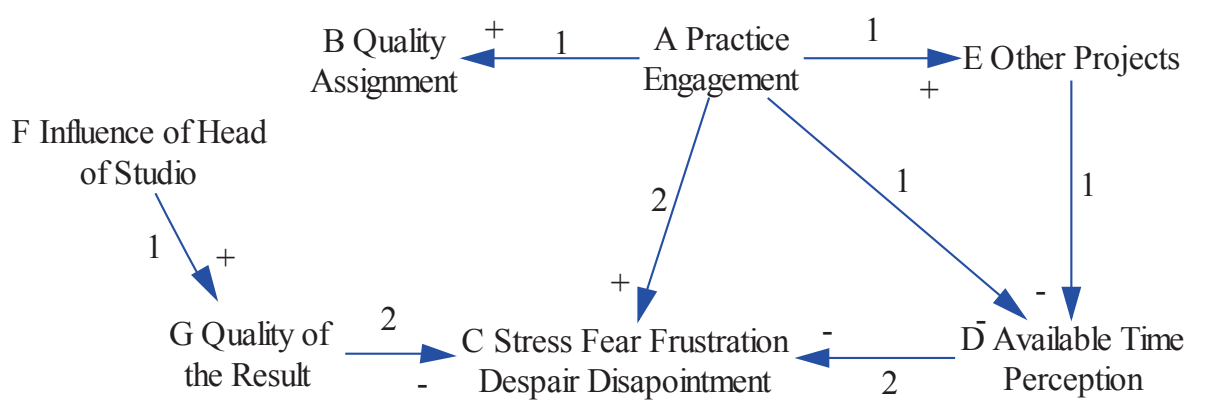

Figure 4. Axial coding diagram. Own source, 2018.

\section{Step 3: Selective coding}

The causalities identified in Figure 4 indicate relations between singular categories only. In order to convert this into a Stock Flow Diagram the central category and reciprocal feedback have to be identified. Selective coding is used to achieve this. The researchers linked the following variables (categories): Practical Experience and Influence of Studio Head, as the studio head seeks out and approves collaboration opportunities with commercial companies, and one cannot be sure there will be any further collaboration. If the students are under too much stress and they cannot achieve the desired product quality they are unlikely to contact the studio head. The more stress, the fewer consultations. There is an additional relationship linking Stress, Frustration, Fear, Despair and Disappointment with Influence of Studio Head.

During follow-up interviews we conducted with the students about the validity of the causal relationship between Stress, Frustration, Fear, Despair, Disappointment and Influence

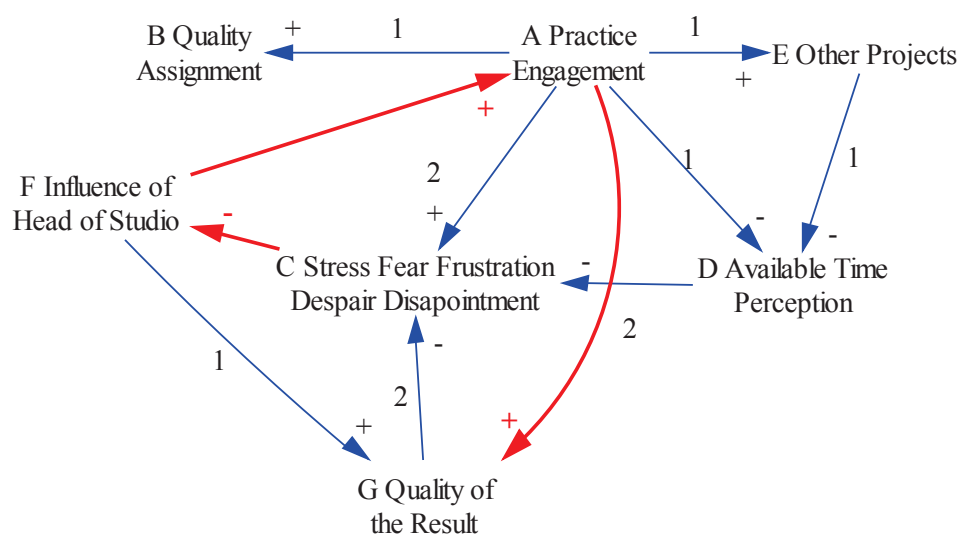

Figure 5. Selective coding. Identifying the central category and further relations. Own source, 2018. 
of Studio Head, most of the students confirmed that they do not consult the head on product development when they are stressed. However, these interviews were not included in the research plan and no records were made of them. The third relationship results from the advantageousness of the collaboration between the university and businesses. The practical assignment improves product quality. The students do not work on designs nobody is interested in, but work on assignments that arise out of communication with the client. Therefore, Practical Experience is linked to Quality of Outcome. The final scheme of causality, which is arrived at through the selective coding that identifies the relationships between the central category and other categories, is shown in Figure 5.

\section{Step 4: Systems thinking}

Quality of Outcome was selected as the central category. However, the models lacks an explanation of how the categories work as a dynamic system. For this purpose a target/ driver needs to be identified. The suggested variable, typically found in every project in this training setting, is Studio Head's Target. (Figure 6. Causal Loop Diagram, CLD)

At the core of the CLD is loop R1, which is a reinforcing loop (the sum of causal directions is positive:,,,++--$)$. The R1 can be interpreted as follows: the studio head exerts a strong influence in the studio (F Influence of Studio Head) and ensures there is strong relation between the students and the practical component (Practical Experience). This step ensures a better quality outcome ( $G$ Quality of Outcome), and better quality reduces the students' stress (C Stress Fear Frustration Despair Disappointment). Under less stress, the

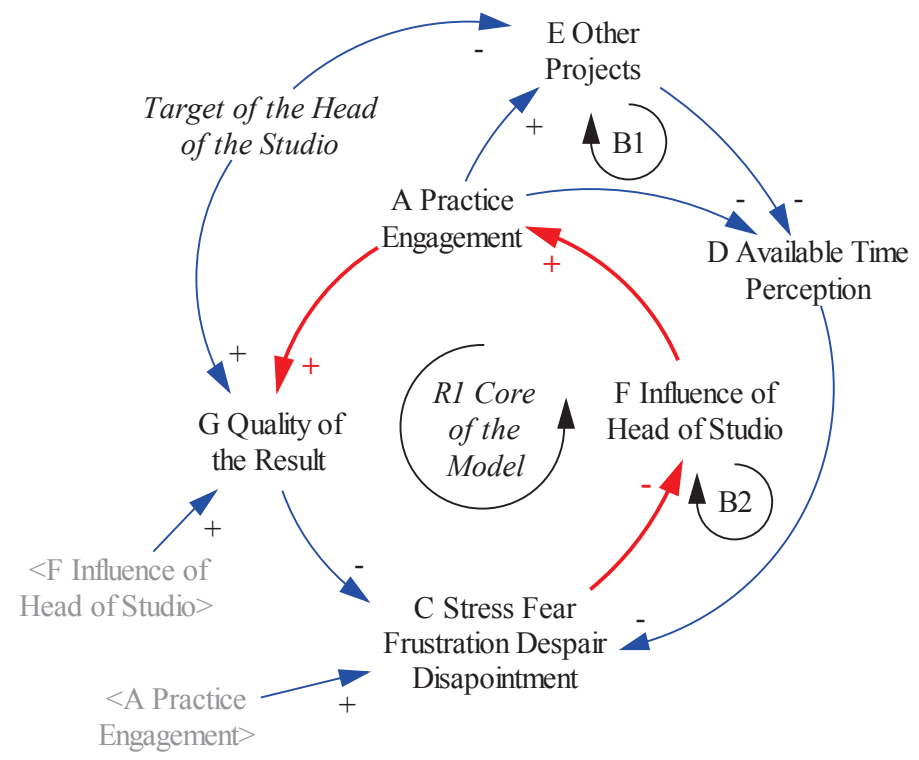

Figure 6. Causal Loop Diagram. Own source, 2018. 
students consult the studio head more, reinforcing the head's influence on the work in the studio. The studio head therefore turns to other companies/customers so the students can collaborate with companies more and gain experience ....again the quality increases.

\section{Step 5: System dynamics (sd) model}

The dynamic hypothesis arrived out through the series of previous analytical processes has to be tested using the system dynamics model. The SD model is based on the CLD and the stock and flow dynamics (Forrester, 1971). The variables in the model operate in accordance with the dynamic hypotheses shown in the CLD (Figure 6).
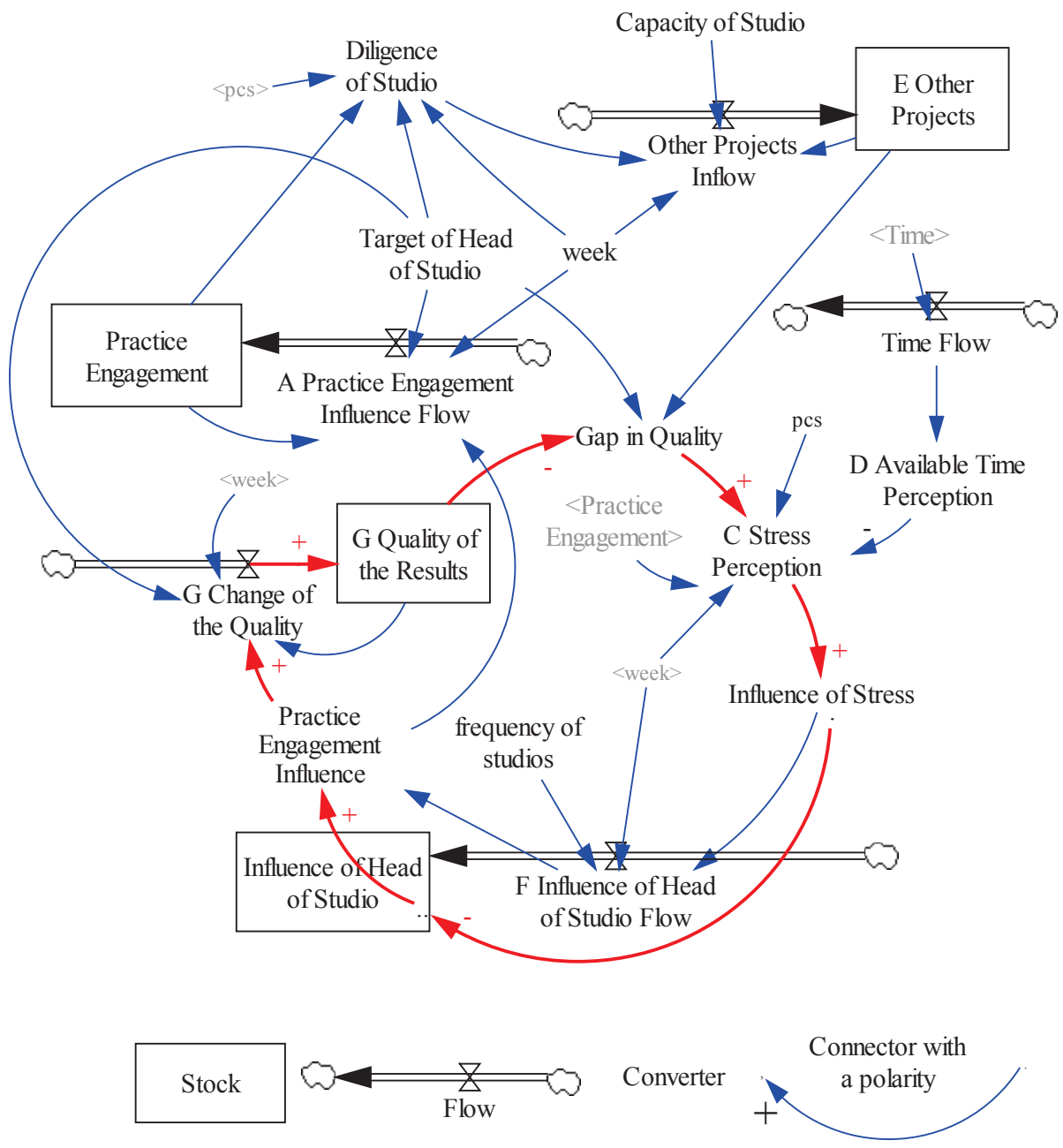

Figure 7. Stock and Flow Diagram. Own source, 2018. 
The model is constructed on the basis of the stock and flow visualization. The process begins with the selection of the endogenous variables that are modeled as stocks. In our study the stocks are: G Quality of Outcome, F Influence of Studio Head, Practical Experience, $F$ Other Projects. The model was developed iteratively. The validity of the dynamic hypotheses set in the CLD (Figure 6) was verified during each stage of the model construction. When constructing the model the rule about the consistency of units was adhered to and continuously applied. Each individual variable that was added is measured in set units and justified by the system of beliefs they are coherent with (Zolfagharian et al., 2014).

The feedback loop, the core of the model, is the equivalent of the dynamic hypothesis expressed in Figure 7. Changes in the main variable, G Quality of Outcome, are caused by the flow of the remaining stocks whose dynamics are monitored in the system dynamics model.

In order to simplify the model description, other feedback loops that may have a major influence on the main variable being monitored (G Quality of Outcome) are not highlighted.

The time available for students to work on the project - to conceive of, draft, create and hand in the designs/prototypes of the products is 30 weeks (in two semesters). There is only one exogenous variable in the model that affects the quality of the students' work, the Studio Head's Target. Other exogenous elements (constants) have no effect on the behavior of the model.

\section{The relations between the categories A, C, F, G}

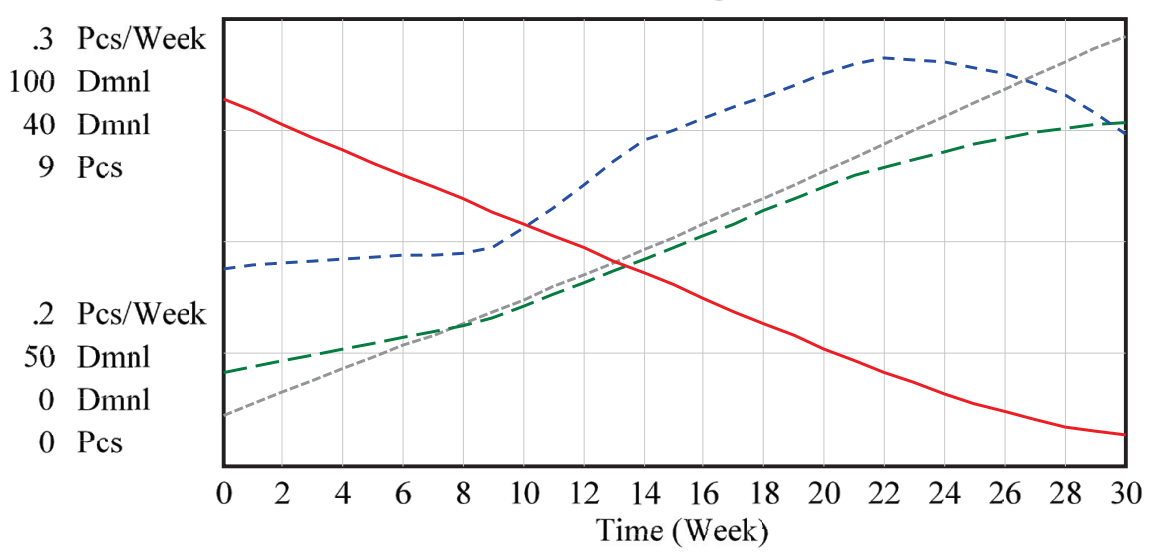

A Practice Engagement Influence Flow: 20 - - - - - - - - - - - - $\quad$ Pcs/Week

C Stress Perception: $20 \quad-$ Dmnl

F Influence of Ilead of Studio Flow: $20--------------$ Dmnl

G Quality of the Results: 20 ---------------------------------------------- Pcs

Figure 8. Studio Head's Target of 20 Pcs. Own source, 2018. (The variable Studio Head's Target is set at 20 products/pieces. This means the studio head is supposed to deliver 20 innovative products over 30 weeks). 


\section{Description of the SD model}

The studio head exerts a strong influence within the studio (F Influence of Studio Head), ensuring a more intensive relationship between the students and the practical experience (Practical Experience). Both categories show dynamic growth. Growth in practical experience changes the quality of the outcome ( $G$ Quality of the Outcome), and improvements in the quality of the product reduce student stress (C Stress Fear Frustration Despair Disappointment). The reduction in stress leads to the students consulting more with the studio head, which increases the head's influence on the outcome of the studio's work. The dynamics hypothesis is shown in Figure 8. It shows the dynamics of the rise and fall of the variables.

\section{Discussion}

In terms of theory of knowledge there are interesting studies exploiting SD modeling in fields where its use would not be expected, such as theatre and drama. Hopkins (1992) was inspired by SD modeling and her 'Hamlet model' focuses on the accumulation of evidence in the plot events that motivate Hamlet to avenge the death of his father and kill Claudius. The case study, which models Hamlet's motivation, employs textual analysis and provides a basis for attempts to apply SD in the humanities and social sciences. The same steps can be used in textual analysis within the Grounded Theory approach. Although Haslett (2006) argues against this approach on the basis that SD modeling is not an effective tool for literary analysis, Hopkins' approach to textual analysis has wider application in qualitative research augmented by quantitative analysis. The time dimension is fundamental to SD modeling. As Haslett puts it: "Stock/flow/rate language is a metaphoric representation of some aspect of reality" (Haslett, 2008).

According to system dynamicists, SD models are reflections of our beliefs about the system of cause and effects (Zolfagharian et al., 2014). Each model provides knowledge around a problem. SD modelers seek to justify "beliefs in variables" about a specific problem so as to obtain an understanding at an approximate level of truth. This is a continual and gradual process, based on the interactions in all the steps of the research methodology/ analysis. The biggest pitfall with this methodology is translating the outcomes of the qualitative analyses into quantitative tools. In our empirical research the role of the soft parameter C Stress Fear Frustration Despair Disappointment interconnected most with the other elements in the system analyzed and during the analysis it evolved as a strong factor affecting the outcome of the design process.

In design thinking, targets can be set as an approximation at the outset. It is an iterative process of customizing design to "customer" demands. This means that both system dynamists and "design thinkers" are continually having to make adjustments. This can be seen in the need to ask questions which have to be verified iteratively, such as "What are the customer's needs? What selection criteria are most important to the customer? Is it possible to verify these claims? Do the variables behave in accordance with the dynamic hypotheses set during the construction of the mental model with feedback loops? Could something occur that the SD model had not taken into account and evaluated?" 
The SD modeler observes model behavior as a prototype for decision-making. The result of the modeling tells us a story. This integral research/analytical methodology includes rational arguments, maps and a story. In this way it builds on phenomenological substance and produces new knowledge that can be used in problem solving in relation to the system being investigated.

\section{Conclusion}

This article is primarily aimed at researchers in the cultural and creative industries who deal with the design thinking process. The two objectives of this article were met: (1) To employ a complete/integral combination of research/analytical methods and (2) to identify the main problems regarding design studio processes. Further improvements can be made and the SD model can be adjusted. During the analysis, the researchers focused on questions relating to the quality of the product in the studio. Qualitative research methods were used to create a model design drawing on haphazard data and data from questionnaires and an interview. The Causal Loop Diagram defined loops that can be defined in the system and it also defined the dynamic hypothesis (see the fourth step of the analysis). The studio head had a strong influence in the studio ( $F$ Influence of Studio Head), fostering stronger collaboration between the students and companies (Practical Experience). Variables ensure a higher quality in the result ( $G$ Quality of Outcome), and in turn reduced the students' stress (C Stress Fear Frustration Despair Disappointment). Under less stress, the students consulted more with the studio head, reinforcing the head's influence on the outcome of the studio work. The head involves other companies so the students can work with other stakeholders/companies giving their work a more practical focus and improving the quality of their work.

This paper is also an innovative contribution to the application of the theory of knowledge in the social sciences and humanities. The application of the integral procedure of Design Thinking and System Dynamics involves a mixed approach that is both qualitative and quantitative.

\section{References}

Ambrose, G., \& Harris, P. (2011). Grafický design: designové myšlení (The fundamentals of creative design). Brno: Computer Press.

Bureš, V., \& Rácz, F. (2017). Identification of sustainability key factors based on capturing dominant feedbacks of behavioural stereotypes in socio-economic systems. Systems, 5(2), 42.

Forrester, J. (1971). Counterintuitive behavior of social systems. Technology Review, 73(3), 52-68.

Haslett, T. (2008). Simulating Hamlett: A critique. System Dynamics Revue, 8(1), 91-98.

Hopkins, P. Lee (1992). Simulating Hamlet in the classroom. System Dynamics Review, 8(1).

Knapp, J., \& Zeratsky, J. , \& Kowitz, B. (2016). Sprint: How to solve big problems and test new ideas in just five days. London: Bantam Press.

Lawson, B. (1980) How designers think: The design process demystified. London: Architectural.

Mildeová, S. (2013). Research problem description and definition: from mental map to connection circle. Journal on Efficiency and Responsibility in Education and Science, 6(4), 328-335.

Richardson, G. P., \& Pugh, A.L. III. (1981). Introduction to system dynamics modeling with DYNAMO. Cambridge, Mass.: MIT Press. 
Richardson, G. P. (1986). Problems with causal-loop diagrams. System Dynamics Review, 2(2), 158170.

Simonsen, J., \& Friberg, K. (2014). Collective analysis of qualitative data. In J. Simonsen et al. (Eds.), Situated design methods (pp. 99-117). Cambridge, Mass.: MIT Press.

Soukalová, R. (2016). The role of universities in the transfer of innovations in the creative industry in the Czech Republic. Proceedings of the 27th International Business Information Management Association Conference - Innovation Management and Education Excellence Vision 2020: From Regional Development Sustainability to Global Economic Growth, IBIMA, pp. 3166-3174.

Sterman, J. D. (1991). A skeptic's guide to computer models. In G. O. Barney et al. (Eds.), Managing a nation: The Microcomputer Software Catalog (pp. 209-229). Boulder, CO: Westview Press.

Sterman, J. (2000). Business dynamics: Systems thinking and modeling for a complex world. Boston: Irwin/McGraw-Hill.

Strauss, A. L., \& Corbin, J. M. (1999). Základy kvalitativního výzkumu : postupy a techniky metody zakotvené teorie. Boskovice: Albert.

Vemuri, P., \& Bellinger, G. (2017). Examining the use of systemic approach for adoption of systems thinking in organizations. Systems, 5(3), 43.

Von Bertalanffy, L. (1968). General system theory: Foundations, development, applications. New York: George Braziller.

Zolfagharian, M., Akbari, R., \& Fartookzadeh, H. (2014). Theory of knowledge in system dynamics models. Foundations of Science, 19(2), 189-207.

Faculty of Multimedia Communications

Tomas Bata University in Zlín

Štefánikova 2431,

76001 Zlín

Czech Republic

E-mail: svirakova@utb.cz

Institute for Research in Social Communication,

Dúbravská cesta 9 ,

Slovak Academy of Sciences,

84104 Bratislava,

Slovakia

E-mail: gabriel.bianchi@savba.sk 